\title{
AEROGEL BEADS AS CRYOGENIC THERMAL INSULATION SYSTEM
}

\author{
J.E. Fesmire ${ }^{a}$, S.D. Augustynowicz ${ }^{b}$, and S. Rouanet ${ }^{\mathrm{c}}$ \\ ${ }^{a}$ NASA Kennedy Space Center, YA-F2-T \\ Kennedy Space Center, Florida, 32899, USA \\ ${ }^{b}$ Dynacs Inc., DNX-3 \\ Kennedy Space Center, Florida, 32899, USA \\ ${ }^{c}$ Cabot Corporation \\ Tuscola, Illinois, 61953, USA
}

\begin{abstract}
An investigation of the use of aerogel beads as thermal insulation for cryogenic applications was conducted at the Cryogenics Test Laboratory of NASA Kennedy Space Center. Steady-state liquid nitrogen boiloff methods were used to characterize the thermal performance of aerogel beads in comparison with conventional insulation products such as perlite powder and multilayer insulation (MLI). Aerogel beads produced by Cabot Corporation have a bulk density below 100 kilograms per cubic meter $\left(\mathrm{kg} / \mathrm{m}^{3}\right)$ and a mean particle diameter of 1 millimeter $(\mathrm{mm})$. The apparent thermal conductivity values of the bulk material have been determined under steady-state conditions at boundary temperatures of approximately 293 and 77 kelvin $(\mathrm{K})$ and at various cold vacuum pressures (CVP). Vacuum levels ranged from $10^{-5}$ torr to 760 torr. All test articles were made in a cylindrical configuration with a typical insulation thickness of $25 \mathrm{~mm}$. Temperature profiles through the thickness of the test specimens were also measured. The results showed the performance of the aerogel beads was significantly better than the conventional materials in both softvacuum ( 1 to 10 torr) and no-vacuum (760 torr) ranges. Opacified aerogel beads performed better than perlite powder under high-vacuum conditions. Further studies for material optimization and system application are in progress.
\end{abstract}




\section{INTRODUCTION}

Studies of thermal insulation systems are a key technology focus area of the Cryogenics Test Laboratory at the NASA Kennedy Space Center. The development of costeffective, robust cryogenic insulation systems that operate at soft-vacuum level (approximately 1 to 10 torr) is a primary target, from an energy and economics point of view, as previously described in reference [1]. This applied research and development work includes the test, evaluation, characterization, and application of silica aerogel beads produced by Cabot Corporation. Over 60 liquid nitrogen boiloff tests using research cryostats have been conducted. These tests include a range of different environments and material combinations. The thermal performance data obtained are being used in the preliminary development of future space travel and space launch applications. Other characterization information such as evacuation, outgassing, and ease of use is also being obtained.

\section{EXPERIMENTAL}

The liquid nitrogen boiloff method utilizing a cylindrical cryostat was used for all tests. Cryostat- 1 is a calorimeter apparatus for direct measurement of the apparent thermal conductivity ( $k$-value) of a material system at a fixed vacuum level [2]. The configuration includes a 1-meter- $(\mathrm{m})$ long cylindrical cold mass with liquid nitrogen guard chambers. The steady-state measurement of the apparent $\mathrm{k}$-value is made when the vacuum level, all temperatures, and the boiloff flow are stable. Cryostat-2 (shown in FIGURE 1) is a calorimeter apparatus for calibrated measurement of the $\mathrm{k}$-value that includes a $1 / 2$-m-long cylindrical cryostat with a removable cold mass. This apparatus allows quicker testing of different specimens and is convenient for materials screening. The CVP is adjusted for the desired vacuum level. Test articles are heated and evacuated to below $10^{-4}$ torr to begin a test series. The residual gas for all tests is nitrogen.

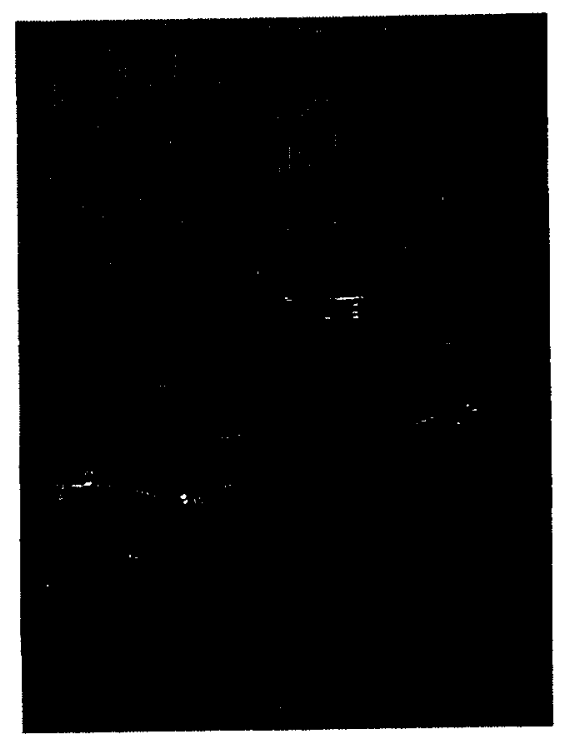

FIGURE 1. Overall view of the insulation test apparatus (Cryostat-2).

The temperatures of the cold mass, insulation layers, containment sleeve [warm boundary temperature (WBT)], and vacuum can are measured. When the vacuum level, all 
temperatures, and boiloff flow are stable, the k-value is determined from Fourier's law of heat conduction for a cylindrical wall [(EQUATION (1)]:

$$
k \text {-value }=\left[M \times H_{f g} \times \ln \left(D_{0} / D_{i}\right)\right] /\left[2 \times \pi \times L_{e f f} \times\left(T_{0}-T_{i}\right)\right]
$$

where:

$$
\begin{aligned}
& T_{o}=\text { WBT, } \mathrm{K} \\
& T_{i}=\text { cold boundary temperature }(\mathrm{CBT}), \mathrm{K} \\
& D_{o}=\text { outer bellows mean diameter, millimeter }(\mathrm{mm}) \\
& D_{i}=\text { inner bellows mean diameter, } \mathrm{mm} \\
& L_{e f f}=\text { effective length of cold mass test chamber, meter }(\mathrm{m}) \\
& m=\text { boiloff flow rate, gram per second }(\mathrm{g} / \mathrm{s}) \\
& h_{f g}=\text { heat of vaporization, joule per gram }(\mathrm{J} / \mathrm{g})
\end{aligned}
$$

The k-value is the apparent thermal conductivity for total insulation system, in milliwatts per meter-kelvin $(\mathrm{mW} / \mathrm{m}-\mathrm{K})$. The thermal shroud maintained the warm boundary surface at approximately $293 \mathrm{~K}$, while the cold mass maintained the cold boundary at approximately $80 \mathrm{~K}$.

The basic test parameters were:

- Boundary temperatures: approximately $80 \mathrm{~K}$ and $293 \mathrm{~K}$

- Nominal thickness: $25 \mathrm{~mm}$

- CVP: from $1 \times 10^{-5}$ torr to 760 torr

- Residual gas: nitrogen

The materials tested were:

- Aerogel beads: $25.4 \mathrm{~mm}, 81 \mathrm{~kg} / \mathrm{m}^{3}$

- Opacified aerogel beads: $25.4 \mathrm{~mm}, 94 \mathrm{~kg} / \mathrm{m}^{3}$ (carbon black R300)

- Perlite powder: $25.4 \mathrm{~mm}, 115 \mathrm{~kg} / \mathrm{m}^{3}$ (50 by $50 \mathrm{mesh}$ )

- Multilayer insulation (MLI): $21.3 \mathrm{~mm}, 92 \mathrm{~kg} / \mathrm{m}^{3}$ (60 layers)

The values for density and thickness correspond to the installed condition. The MLI specimens were composed of aluminum foil and fiberglass paper, as is typically used for highly evacuated cryogenic insulation systems.

\section{AEROGEL BEAD PRODUCTION AND PROPERTIES}

The production of aerogel beads is summarized in FIGURE 2. A continuous process of manufacturing is employed. Views of the drying system are given in FIGURE 3. The ambient drying step replaces the costly supercritical drying step characteristic of most aerogels produced by solution and gelation (sol-gel) methods. The novel features and benefits of the aerogel bead production are summarized as follows: 


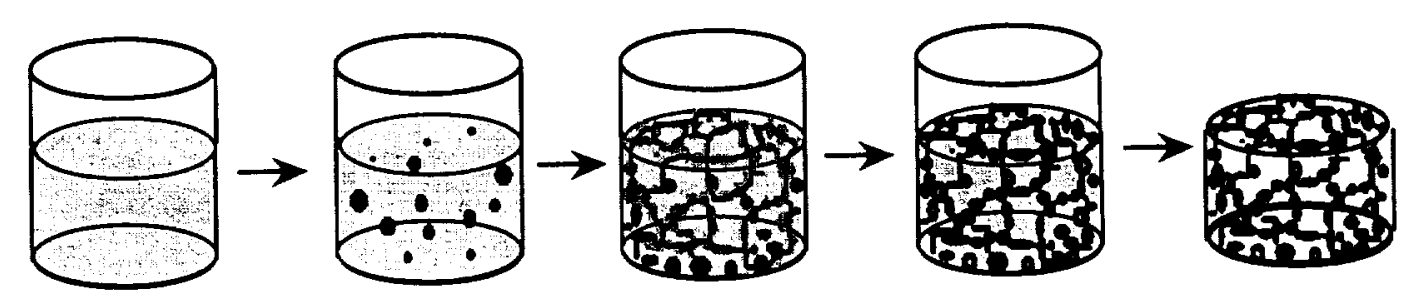

\section{Waterglass \\ Sol Hydrogel \\ Silation \\ Aerogel}

FIGURE 2. Stages in the production of silica aerogel beads.
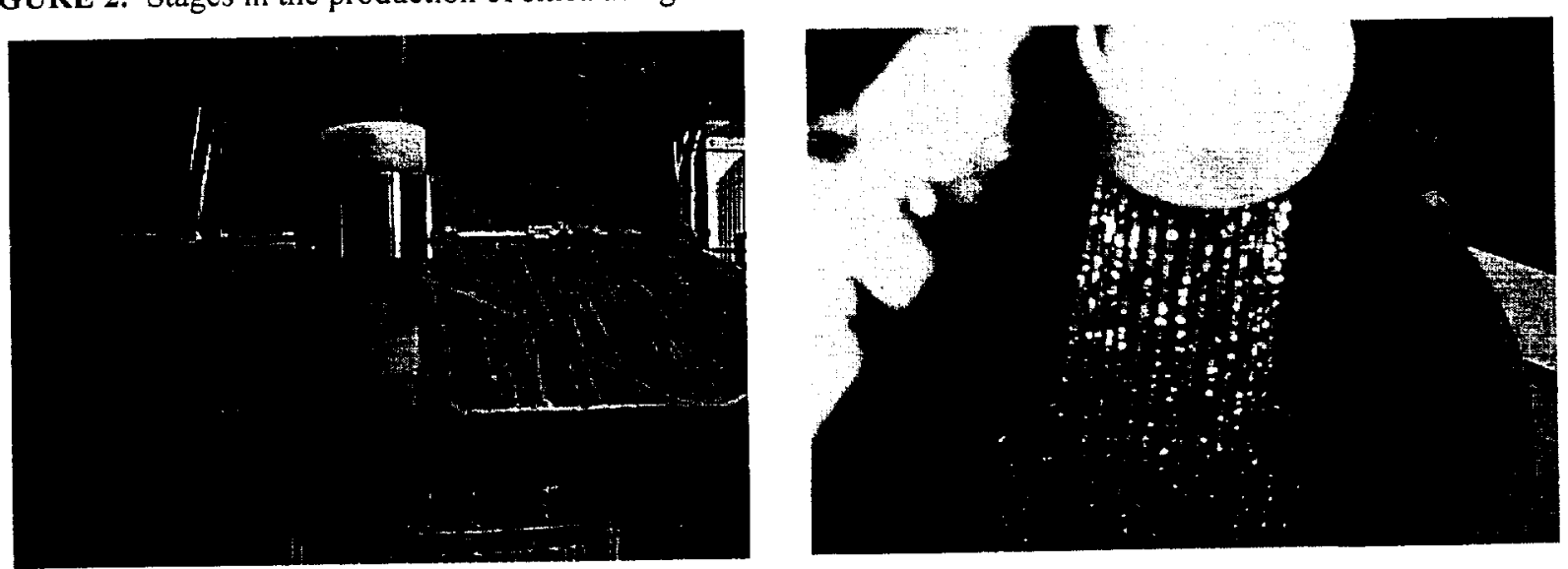

FIGURE 3. Spraying system for the production of aerogel beads: (left) overall view, (right) spray head.

- Economical precursor: sodium silicate

- Bead formation using high-throughput spray nozzle

- High product consistency

- Narrow bead size distribution

- Aerogel produced by low-cost process

- Surface sylation of hydrogel

- Ambient pressure drying

The properties of aerogel beads are:

- Nominal diameter: $1 \mathrm{~mm}$

- Bead density: $140 \mathrm{~kg} / \mathrm{m}^{3}$

- Bulk density: $80 \mathrm{~kg} / \mathrm{m}^{3}$

- Surface area: 650 square meters per gram $\left(\mathrm{m}^{2} / \mathrm{g}\right)$

- Pore volume: 3.17 cubic centimeters per gram $\left(\mathrm{cm}^{3} / \mathrm{g}\right)$

- Outgassing: less than 1 percent total mass loss

- Flammability: noncombustible

- Minimum ignition temperature: 400 degrees Celsius $\left({ }^{\circ} \mathrm{C}\right)$

The beads are treated to remain hydrophobic, but a hydrophilic (untreated) product is also available for oxygen service. The pore size distribution for the material is shown in FIGURE 4. The typical diameter of the particles is indicated by the graph in FIGURE 5. 


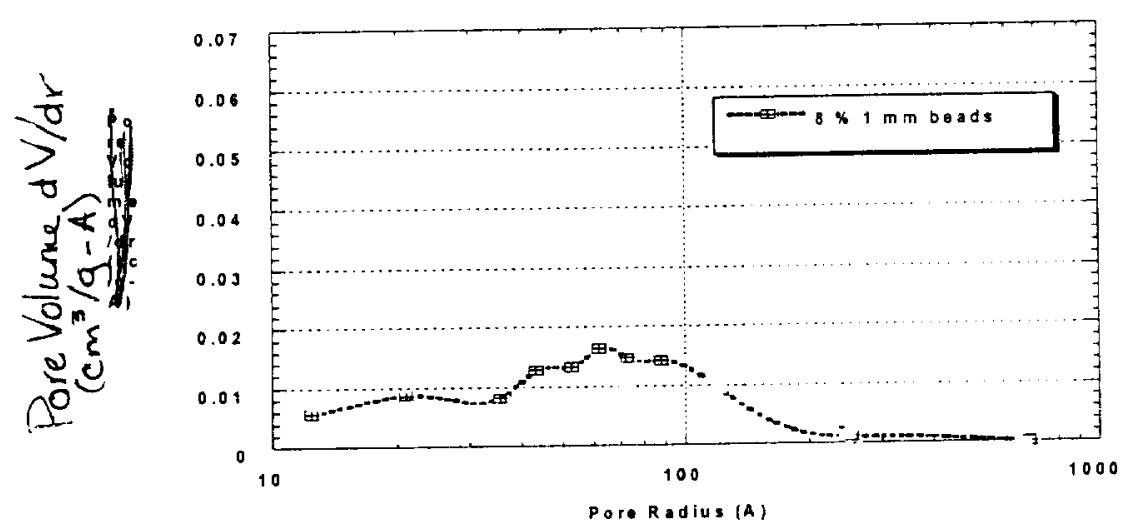

FIGURE 4. Pore size distribution of the aerogel material.

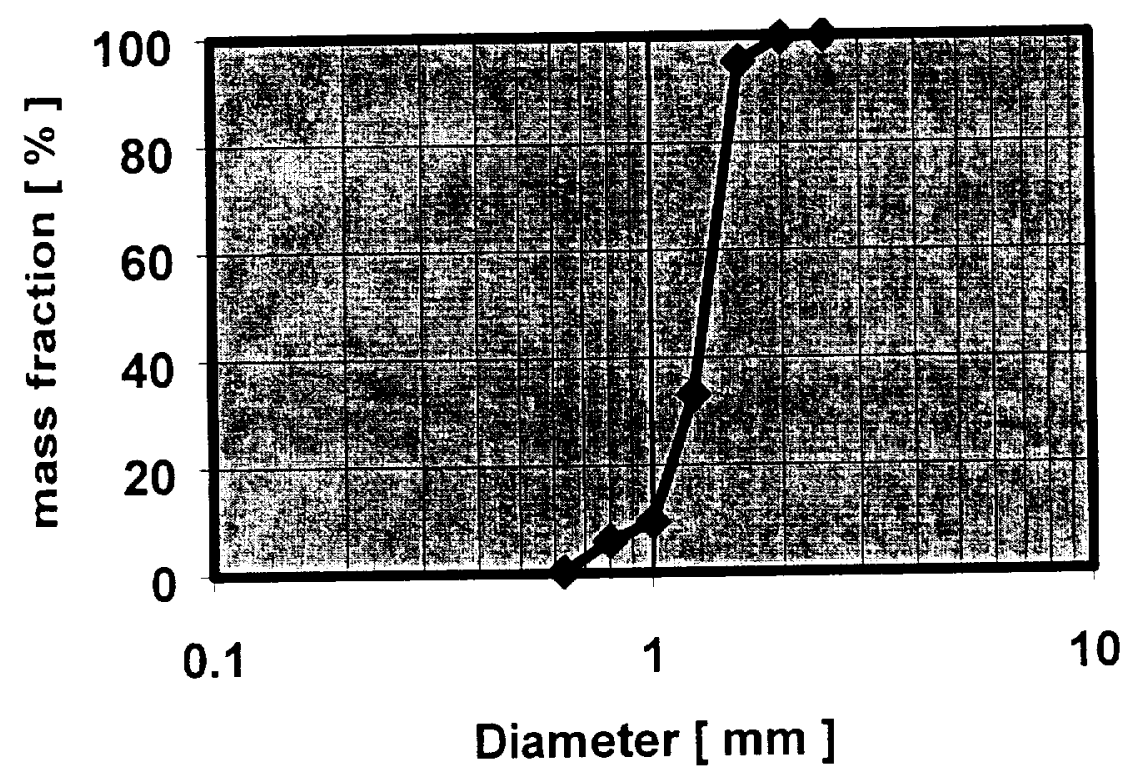

FIGURE 5. Particle size distribution for the aerogel beads.

\section{RESULTS AND DISCUSSION}

The aerogel beads were tested under cryogenic conditions (liquid nitrogen temperature) and at all vacuum levels from high vacuum to soft vacuum to no vacuum. Materials, including perlite and MLI, were tested under the same conditions and using the exact same methods for comparison purposes. An overall graph of the apparent thermal conductivity ( $\mathrm{k}$-value) as a function of the cold vacuum pressure is presented in FIGURE 6. The experimental curves for perlite and MLI compare well with similar thermal performance data from the literature (Adams and Kaganer) $[3,4]$. The aerogel beads gave superior performance for all vacuum levels above 100 millitorr. For example, the k-value for the aerogel beads at 10,000 millitorr was $6.6 \mathrm{~mW} / \mathrm{m}-\mathrm{K}$ versus $27 \mathrm{~mW} / \mathrm{m}-\mathrm{K}$. 


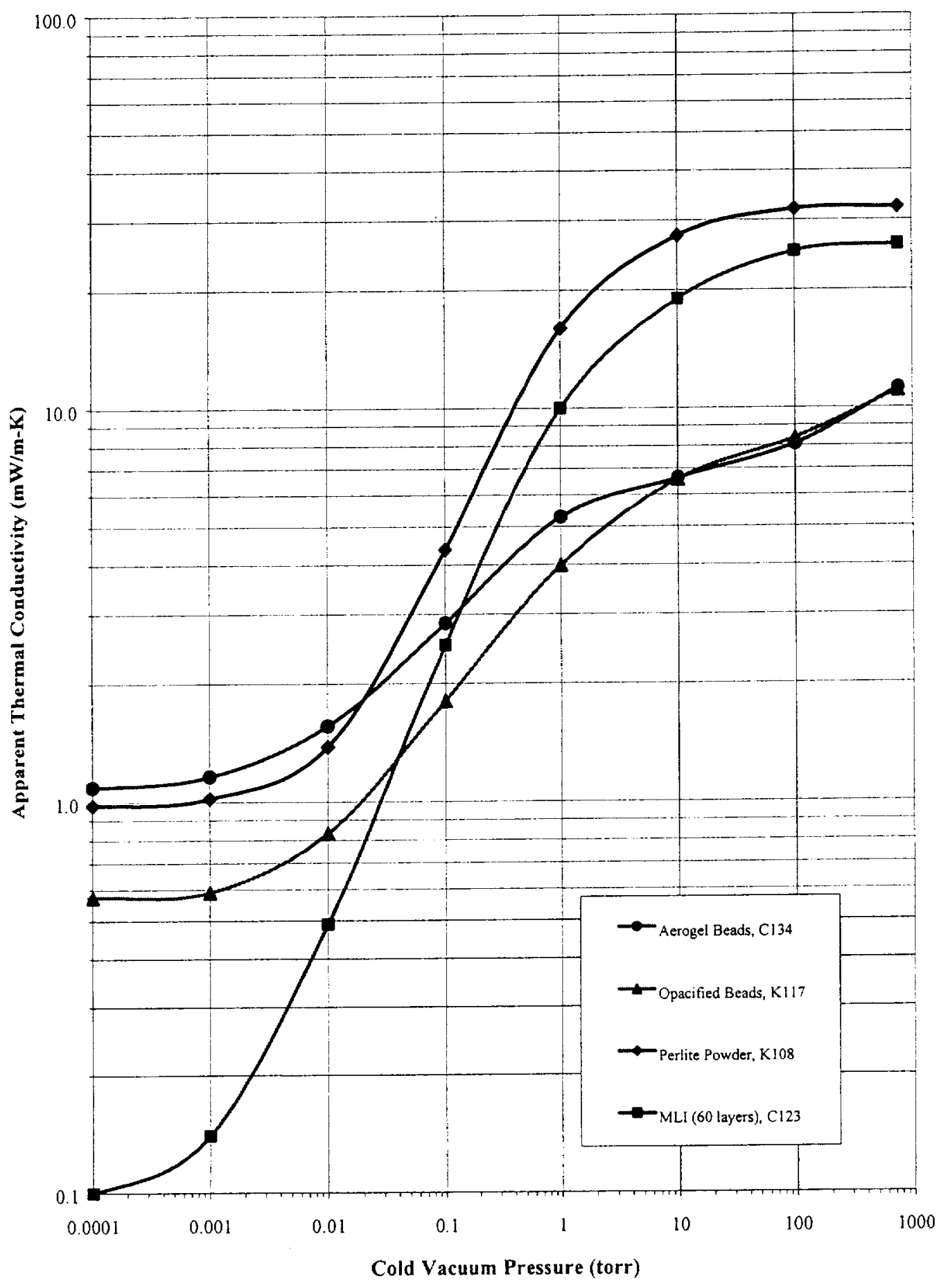

FIGURE 6. Variation of apparent thermal conductivity (k-value) with CVP for different insulation materials.

for perlite. The carbon black opacifier improved the performance of the aerogel beads for CVP's below 10,000 millitorr, while having no effect at no-vacuum conditions. As expected, the graphs clearly show that radiation begins to dominate the modes of heat transfer at vacuum levels below 100 millitorr. The high-vacuum (below 0.1 millitorr) performance of the plain white aerogel beads was approximately $1.1 \mathrm{~mW} / \mathrm{m}-\mathrm{K}$, while that of the opacified specimen was approximately $0.6 \mathrm{~mW} / \mathrm{m}-\mathrm{K}$. The added radiation shielding effect of the opacifier yielded almost 50 percent improvement for the aerogel beads. The experimental 
$\mathrm{k}$-values for the aerogel beads were found to be comparable to the performance of other aerogel-based products under similar cryogenic vacuum conditions: that is, around 1 $\mathrm{mW} / \mathrm{m}-\mathrm{K}$ or less under high vacuum and about $10 \mathrm{~mW} / \mathrm{m}-\mathrm{K}$ in ambient pressure [5]. The bulk density of the beads was $81 \mathrm{~kg} / \mathrm{m}^{3}\left(94 \mathrm{~kg} / \mathrm{m}^{3}\right.$, opacified), which is similar to that of the MLI and 30 percent less than that of the perlite.

\section{CONCLUSIONS}

The results of this experimental research study of aerogel beads show this new product offers several performance advantages compared to the more conventional thermal insulation products currently available for cryogenic applications. Some key advantages of the aerogel beads are:

- Free flowing, fills small cavities

- Minimal dusting

- Nonsettling, does not compact

- No preconditioning needed

- Can be molded or formed using binders

The thermal performance, in terms of apparent thermal conductivity ( $k$-value) for boundary temperatures between liquid nitrogen temperature and room temperature, was determined to be approximately $11 \mathrm{~mW} / \mathrm{m}-\mathrm{K}$ at no vacuum and $1.1 \mathrm{~mW} / \mathrm{m}-\mathrm{K}(0.6 \mathrm{~mW} / \mathrm{m}$ $\mathrm{K}$, opacified) at high vacuum. Note that the bulk density was only $81 \mathrm{~kg} / \mathrm{m}^{3}\left(94 \mathrm{~kg} / \mathrm{m}^{3}\right.$, opacified) while the individual bead density was $140 \mathrm{~kg} / \mathrm{m}^{3}$.

The basic aerogel bead material has numerous possibilities for thermal insulation uses in cryogenic and other higher performance insulation needs in industry. The material is already being utilized as a cavity-packing material for research cryostat applications. Various evaluation activities are being performed at the NASA Ames Research Center, Marshall Space Flight Center, and Kennedy Space Center. This work includes novel composite constructions and larger-scale applications such as cold boxes. The material has been proposed for insulating cryogenic umbilical connections for new commercial launch platforms, retrofit perlite-insulated storage dewars, and insulation of a miles-long cryogen transfer line.

Looking for cost-effective solutions to insulation problems is fundamental to the energy-intensive field of cryogenics and, in general, to the endeavors of space travel. A successful production chain for aerogel beads and similar nano-technology materials will be an important part of these efforts. Maturation of the production processes can then lead to wide-scale usage in practically all refrigeration industries including food processing, storage, and transportation; air conditioning and environmental control; medical and biological applications; manufacturing processes; and other industry applications.

\section{REFERENCES}

1. Augustynowicz, S.D., Fesmire, J.E., and Wikstrom, J.P., "Cryogenic Insulation Systems," in $20^{\text {th }}$ International Refrigeration Congress 2000-1147, International Institute of Refrigeration, Paris, 1999.

2. Fesmire, J.E., Augustynowicz, S.D., "Insulation Testing Using Cryostat Apparatus With Sleeve," $A d-$ vances in Cryogenic Engineering, Vol. 45, Kluwer Academic/Plenum Publishers, New York, 2000, pp. $1683-1690$. 
3. Adams, L., "Thermal Conductivity of Evacuated Perlite," in Cryogenic Technology Journal of the Cryogenic Society of America, Vol. 1, No. 6, 1965, pp. 249-251.

4. Kaganer, M.G., "Thermal Insulation in Cryogenic Engineering," in Israel Program for Scientific Translations, Inc., IPST Press, Jerusalem, 1969, pp. 114-116.

5. Fesmire, J.E., Rouanet, S., and Ryu, J., "Aerogel-Based Cryogenic Superinsulation," in Advances in Cryogenic Engineering, Vol. 44, Plenum Press, New York, 1998, pp. 219-226. 